\title{
Thyroid function during critical illness
}

\author{
Foteini Economidou, Evangelia Douka, Marinella Tzanela, Serafeim Nanas, \\ Anastasia Kotanidou
}

Department of Intensive Care Medicine, University of Athens, Evangelismos Hospital, Department of Endocrinology, Evangelismos Hospital, Athens, Greece

\begin{abstract}
The metabolic support of the critically ill patient is a relatively new target of active research and little is as yet known about the effects of critical illness on metabolism. The nonthyroidal illness syndrome, also known as the low $\mathbf{T}_{3}$ syndrome or euthyroid sick syndrome, describes a condition characterized by abnormal thyroid function tests encountered in patients with acute or chronic systemic illnesses. The laboratory parameters of this syndrome include low serum levels of triiodothyronine $\left(T_{3}\right)$ and high levels of reverse $T_{3}$, with normal or low levels of thyroxine $\left(\mathbf{T}_{4}\right)$ and normal or low levels of thyroid-stimulating hormone (TSH). This condition may affect 60 to $70 \%$ of critically ill patients. The changes in serum thyroid hormone levels in the critically ill patient seem to result from alterations in the peripheral metabolism of the thyroid hormones, in TSH regulation, in the binding of thyroid hormone to transport-protein and in receptor binding and intracellular uptake. Medications also have a very important role in these alterations. Hormonal changes can be seen within the first hours of critical illness and, interestingly, these changes correlate with final outcome. Data on the beneficial effect of thyroid hormone treatment on outcome in critically ill patients are so far controversial. Thyroid function generally returns to normal as the acute illness resolves.
\end{abstract}

Key words: Critical illness, Euthyroid sick syndrome, Low $T_{3}$ syndrome, Metabolic physiology, Thyroid gland function

\section{INTRODUCTION}

The metabolic responses to sepsis involve every organ and tissue of the body and yet, surprisingly, little is known about the underlying mechanisms. During sepsis and other critical illnesses, the state of

Address for correspondence:

Foteini Economidou MD, PhD, Department of Intensive Care Medicine of University of Athens, "Evangelismos" General Hospital, 45-47 Ipsilantou Str, GR 10675 Athens, Greece, Tel: +30 2107201923, E-mail: foikon@yahoo.gr Received 09-09-10, Revised 10-01-11, Accepted 25-01-11 stress results in hypermetabolism, increased energy expenditure, hyperglycemia and muscle loss. ${ }^{1,2}$ It is anticipated that appropriate metabolic support could improve the outcome in these patients, but considerable controversy remains regarding the indicated therapeutic approach.

Critical illness is often associated with alterations in thyroid hormone concentrations in patients with no previous intrinsic thyroid disease. ${ }^{3-5}$ Changes in parameters of thyroid function are very common but 
rarely isolated. They are often associated with alterations in other endocrine axes (reductions in serum gonadotropin and sex hormone concentrations and increases in serum adrenocorticotropic hormone and free cortisol levels). ${ }^{6,7}$ Thus, the sick euthyroid syndrome should not be viewed as an isolated abnormal event but as part of a generalized systemic endocrine response to illness.

In this article, we will summarize the current knowledge on the status of thyroid hormones in the critically ill patient. In order to correctly interpret thyroid function tests (TFTs), the intensivist should be familiar with the changes that occur during critical illness in the function of the hypothalamic-pituitarythyroid axis and in thyroid hormone metabolism as well as the effects of commonly used medications on thyroid physiology (Table 1).

\section{THYROID HORMONES IN CRITICAL ILLNESS}

(Tables 2,3)

\section{Triiodothyronine (T3)}

$\mathrm{T} 3$ is the biologically active thyroid hormone and its low serum levels in critical illness reflect altered thyroid homeostasis and a mechanism of adaptation. Normally most $(80 \%-90 \%)$ of T3 is produced by monodeiodination of $40 \%$ of circulating $\mathrm{T} 4$, a reaction catalyzed by 5 '-monodeiodinases in organs such as the liver and kidney (Figure 1). The remaining $(10 \%-20 \%)$ is directly secreted by the thyroid gland.

Table 1. Drugs causing alterations in thyroid function and mechanisms involved

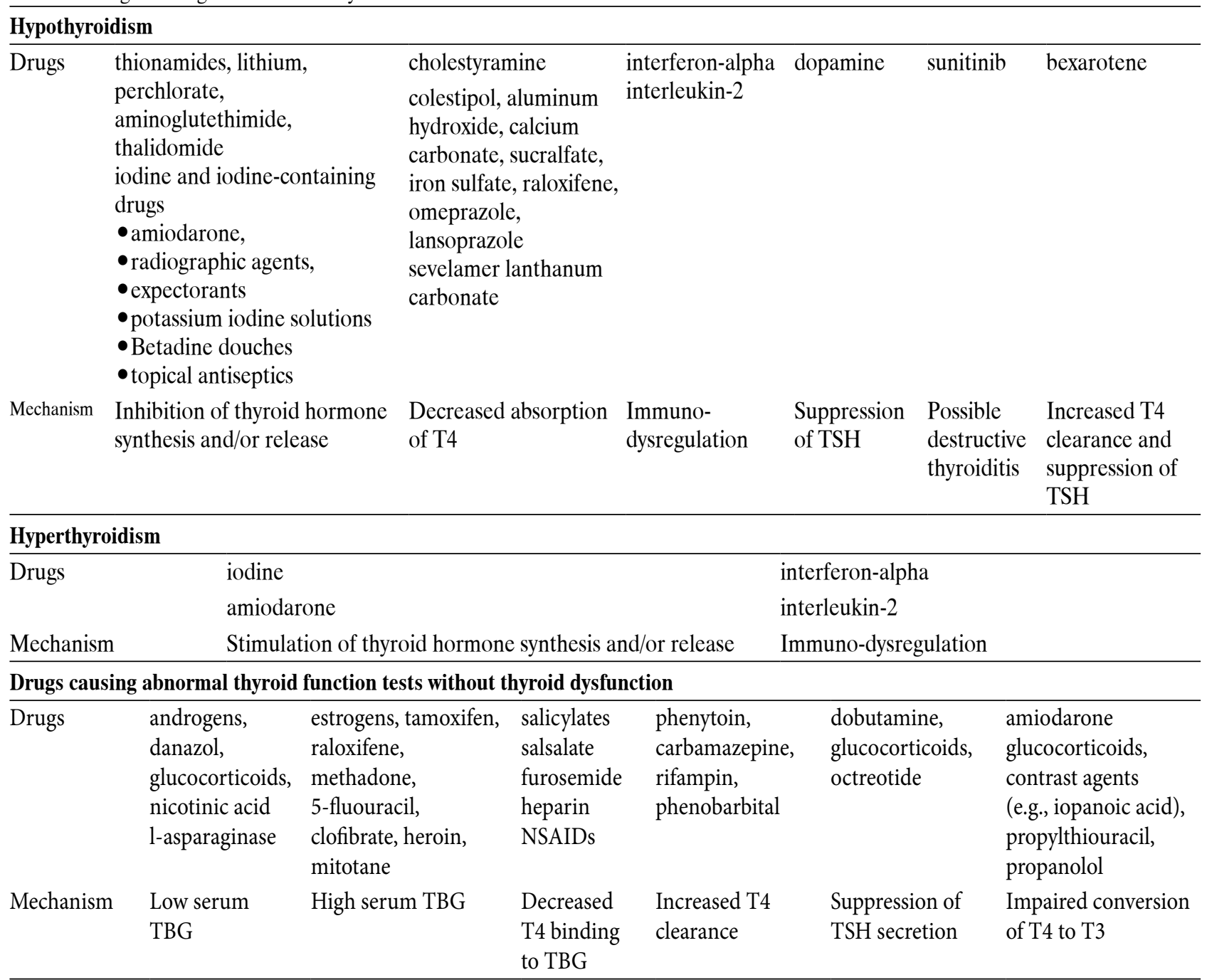


Table 2. TSH values during critical illness and clinical outcome

\begin{tabular}{lll}
\hline & Serum TSH values $(\mathbf{m U} / \mathbf{L})$ & Diagnosis, outcome \\
\hline Undetectable & $<0.01$ & Hyperthyroidism or non- thyroidal illness (a) \\
Low but detectable & $>0.05$ and $<0.3$ & Euthyroidism when reassessed after recovery from their illness \\
High but & $<20$ & Transient (recovery phase) or permanent hypothyroidism(uncommon) \\
High but & $>20$ & Permanent hypothyroidism ${ }^{\mathrm{x}}(\mathrm{b})$ \\
\hline
\end{tabular}

a: Only $75 \%$ of patients with nonthyroidal illness and a TSH $<0.01$ will have hyperthyroidism when recovered from their illness. ${ }^{40}$ b: In patients with a TSH $>20$, only $50 \%$ will have true (permanent) hypothyroidism when recoverd from their illness. ${ }^{52}$

Table 3. Alterations in thyroid hormones during critical illness and their clinical correlation

\begin{tabular}{lllll}
\hline Critical illness & T3 & T4 & TSH & Clinical correlation \\
\hline Acute phase & Decreased & Increased & Normal & Severity of illness \\
Chronic phase & Decreased & Decreased & No change/decreased & May indicate recovery \\
\hline
\end{tabular}

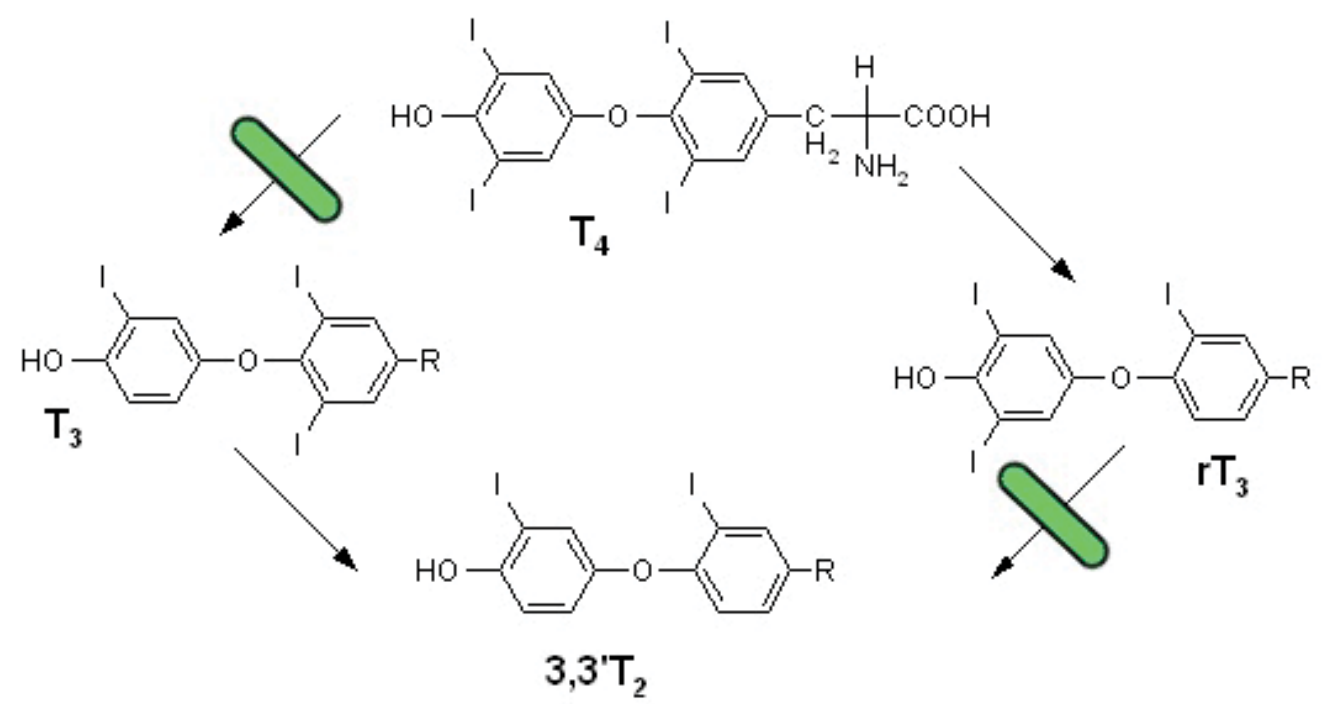

\section{5'-monodeiodinase inhibition reduces T3 production and rT3 metabolism}

Figure 1. Thyroxine metabolism in nonthyroidal illness. The inhibition of 5'-monodeiodinase in nonthyroidal illness leads to decreased conversion of T4 to T3 and reduced metabolism of reverse T3.

Inhibition of the enzyme 5'-deiodinase that catalyzes the conversion of $\mathrm{T} 4$ to $\mathrm{T} 3 \mathrm{~h}$ has been considered a possible mechanism responsible for the sick euthyroid syndrome. ${ }^{8,9}$ Additionally, many drugs that are commonly used in ICU, such as iodine, amiodarone and corticosteroids, also reduce the conversion of T4 to T3.

The majority of critically ill patients have low serum T3 concentrations, as do some outpatients during illness. Liver and skeletal muscle biopsies obtained within minutes after death from intensive care unit patients demonstrate reduced 5'-monodeiodinase activity and increased 5'-monodeiodinase activity (which converts T4 to rT3). ${ }^{10,11}$ Moreover, patients with fatal illness have low tissue T4 and T3 concentrations. ${ }^{12,13}$

Several mechanisms can contribute to the inhibition of 5'-monodeiodination and therefore to the low serum $\mathrm{T} 3$ concentrations in critically ill patients with nonthyroidal illness: 
A. Exogenous glucocorticoid therapy. ${ }^{14}$

B. Circulating inhibitors of deiodinase activity, such as free (non-esterified) fatty acids. ${ }^{15}$

C. Treatment with drugs that inhibit 5'-monodeiodinase activity, such as amiodarone and high doses of propranolol.

D. Cytokines (such as tumor necrosis factor, interferon-alpha, NF-kB and interleukin-6). ${ }^{16-18}$

\section{Reverse triiodothyronine (rT3)}

The initial and most common abnormality observed in any person who has a significant acute illness is a fall in total $\mathrm{T} 3$ concentrations accompanied by an increase in rT3 levels. T4 conversion to rT3 by 5'-deiodinase is called the "inactivating pathway".

The conversion of reverse $\mathrm{T} 3$ to diiodothyronine (T2) is reduced in nonthyroidal illness because of inhibition of the 5 -monodeiodinase activity. ${ }^{19}$ This constitutes an additional mechanism of high serum rT3 values in patients with nonthyroidal illnesses, except in those with renal failure and some patients with AIDS. ${ }^{20,21}$

\section{Thyroxine (T4)}

Serum T4 in nonthyroid illness can be reduced within 24 to $48 \mathrm{hrs}$. The initial decline is predominantly due to decreased binding to carrier proteins, such as thyroid hormone binding globulin (TBG), transthyretin (TTR), or thyroxine-binding prealbumin [TBPA]) and albumin. ${ }^{22}$

Many drugs (Table 1), including salicylates, phenyntoin, carbamazepine, furosemide, compete with thyroid hormone for binding to TBG, resulting in an acute increase in free $T_{4}$ and a decrease in total $\mathrm{T}_{4}$ concentrations. The presence of circulating inhibitors of $\mathrm{T}_{4}$ binding, such as high concentrations of fatty acid, disordered iodine uptake by the thyroid or abnormal peripheral metabolism, are also possibly implicated in the low total and/or free $\mathrm{T}_{4}$ levels. ${ }^{23-26}$ Some drugs including phenytoin, carbamazepine, rifampin, Phenobarbital, may also contribute to low total $\mathrm{T}_{4}$ concentration by accelerating its clearance.

\section{Free T4}

Despite low total $\mathrm{T}_{4}$ in critical illness, serum concentrations of free $T_{4}$ remain in the normal range in most patients unless the illness is severe and protracted. ${ }^{27}$ However, hypothalamic-pituitary suppression, usually present in prolonged critically illness, leads to decreased secretion of $\mathrm{TSH}$, decreased $\mathrm{T}_{4}$ production by the thyroid gland and a subsequent decline of free $\mathrm{T}_{4}$ levels in the circulation, a sign of severity of the disease and a predictor of poor outcome. ${ }^{28}$

\section{Thyrotropin (TSH)}

Under normal conditions, TSH synthesis is relatively stable and is controlled by thyroid hormones, neuropeptides and neurotransmitters. Hypothalamic thyrotropine-releasing hormone (TRH) is the main stimulating factor of TSH synthesis and its effect is enhanced by catecholamines. Somatostatin and dopamine are the main inhibitory factors of TSH synthesis. In euthyroid sick syndrome, TSH levels are commonly within the normal range and only in prolonged illness may be low. Serum TSH assays that have a detection limit of $0.01 \mathrm{mU} / \mathrm{L}$ should be used in assessing thyroid function in critically ill patients. ${ }^{29}$ Some hospitalized patients have transient elevations in serum TSH concentrations (up to 20 $\mathrm{mU} / \mathrm{L}$ ) during recovery from nonthyroidal illness. Few of these patients prove to have hypothyroidism when re-evaluated after recovery from their illness. Patients with serum TSH concentrations over $20 \mathrm{mU} / \mathrm{L}$ usually have permanent hypothyroidism ${ }^{8}$ (Table 2).

Most ICU patients suffer from sepsis. It is supposed that early alterations in the regulation of thyroid hormones economy during sepsis involve mainly peripheral mechanisms, such as impaired peripheral deiodination and reduced thyroid hormone secretion. The late phase of sepsis is associated with centrally induced hypothyroidism as suggested by restoration of T3 and T4 pulses by exogenous TRH infusion. ${ }^{30}$ In addition, postmortem examination showed diminished thyroid gland weight and follicular size, ${ }^{31}$ low expression of TRH messenger RNA in the hypothalamic paraventricular nuclei and low concentrations of tissue T3 in patients who died while in the late phase of sepsis. ${ }^{32,33}$ Common late alteration in thyroid metabolism is a decrease in the pituitary secretion of TSH that typically occurs in parallel with the decline in serum T4 concentrations. ${ }^{34}$ The causes are multifactorial and attributed to effects of the illness per se, malnutrition and the suppressive effects of 
cytokines and medications such as corticosteroids and dopamine. ${ }^{35,36}$ If the illness persists, reduced TSH secretion likely contributes to low total and eventually low free T4 concentrations. Clinically, low T3 and T4 levels, in association with normal, low-normal or decreased TSH, suggest the development of a variant of central hypothyroidism. ${ }^{37}$ Such changes may be a self-protective adaptation to illness, as the body attempts to conserve energy. This state is usually transient, resolving once the patient shows signs of improvement. The recovery of the thyroidal axis begins with a rise in serum TSH and is eventually followed by normalization in T4 concentrations. ${ }^{38}$ Because of the difference in half-lives of T4 (days) and TSH (hours), the normalization of T4 lags behind the increase in TSH. As a result, the picture during the resolution of euthyroid sick syndrome may suggest primary hypothyroidism (Table 3 ).

\section{Assessment of thyroid function in ICU}

The decreased 5'-monodeiodinase activity is often not recognized because measurement of serum $\mathrm{T} 3$ is rarely utilized as a screening test for thyroid function (nor should it be). It is, however, useful to measure serum T3 in hospitalized patients who have a low serum TSH concentration (Table 1) in whom the differential diagnosis is hyperthyroidism versus nonthyroidal illness. The serum T3 value should be high (or high-normal) in hyperthyroidism but low (or low-normal) in nonthyroidal illness. Rarely, a very sick patient with hyperthyroidism will have a low serum T3 concentration. ${ }^{39}$

In the differential diagnosis of low serum $\mathrm{T}_{3}$ and $\mathrm{T}_{4}$ in the critically ill patient, intensivists should include hypothyroidism. Measurements of $\mathrm{rT}_{3}$ had been considered useful in differentiating nonthyroidal illness (high $\mathrm{rT}_{3}$ ) from secondary hypothyroidism (low TSH), which should be associated with low $\mathrm{rT}_{3}$. Subsequent studies however showed that $\mathrm{rT}_{3}$ does not accurately distinguish the two states. ${ }^{37}$

In assessing thyroid function in ICU, two important general principles must be considered: ${ }^{40}$

- Thyroid function should not be assessed in seriously ill patients unless there is a strong suspicion of thyroid dysfunction.

- When thyroid dysfunction is suspected in critically ill patients, measurement of serum TSH alone is inadequate for the evaluation of thyroid function

\section{THYROID HORMONE TREATMENT OF NONTHYROIDAL ILLNESS}

It remains controversial whether development of the aforementioned changes in thyroid metabolism reflects a protective mechanism or a maladaptive process during illness.

If these changes constitute an adaptation mechanism, then treatment to restore thyroid hormone levels to the normal range could have deleterious effects. In contrast, if these changes are pathologic, treatment may improve an otherwise poor clinical outcome. Current literature data indicate that:

1. Starvation-induced decrease in serum $\mathrm{T}_{3}$ concentrations most likely reflects a process of adaptation.

2. Treatment with dopamine and high-dose systemic corticosteroids, generally used in ICU patients, decreases serum TSH concentrations.

3. Alterations in deiodinase enzymes occur in tissues of humans who died in the setting of critical illness. ${ }^{10,41}$

4. Transport of thyroid hormones into target tissues of critically ill patients may also be reduced. ${ }^{42}$

However, clinical measurements of thyroid function with the use of parameters such as the Achilles tendon reflex time, cardiac QKD interval and metabolic rate indicate a euthyroid state. ${ }^{5}$

The presence of euthyroid sick syndrome is associated with increased mortality among critically ill patients. ${ }^{43,44}$ Low serum $\mathrm{T}_{4}$ or low $\mathrm{T}_{3}$ levels seem to be a poor prognostic indicator in hospitalized cardiac patients ${ }^{45,46}$ or in patients after bone marrow transplantation. ${ }^{47}$ Whether this low hormone state could be related to recovery delay indicating therapeutic intervention has not been fully elucidated.

Only a few studies have examined the use of supplemental thyroid hormone therapy in critically ill general medical patients. Brent and Hershman ${ }^{48}$ examined the effect of thyroid hormone therapy in medical intensive care unit patients. The patients included in the study had serum $\mathrm{T}_{4}$ levels $<5 \mu \mathrm{g}$ / 
dL with no evidence of intrinsic thyroid dysfunction and were given either $T_{4}$ or placebo intravenously on a daily basis. There was no significant difference in mortality between the two groups and the $\mathrm{T}_{4}$ replacement was detrimental to the restoration of normal pituitary-thyroid regulation. In organ donors exogenous thyroid hormones stabilizes the function of the cardiovascular system. There have been other trials in patients who suffered acute renal failure or underwent renal transplantation that also failed to show any benefit. ${ }^{49,50}$

One could argue that levothyroxine therapy applied for the management of the euthyroid sick syndrome is not expected to have any effect because of the pronounced inhibition of conversion of $\mathrm{T}_{4}$ to $\mathrm{T}_{3}$ in these patients. It is interesting that hepatic deiodinase is a selenoprotein and selenium deficiency is commonly seen in septic ICU patients. Thus, one could conclude that supplementation with selenium may result in a quicker normalization of $\mathrm{T}_{4}$ and $\mathrm{rT}_{3}$. Becker et al examined the effect of treatment with $\mathrm{T}_{3}$ in 36 patients with acute burn injuries. ${ }^{51}$ Treatment with liothyronine $\left(\mathrm{LT}_{3}\right)$ normalized serum $\mathrm{T}_{3}$ concentrations but resulted in no change in either mortality or basal metabolic rate. Since it is easier to diagnose sick euthyroid syndrome than to treat it properly, avoidance of thyroid hormone substitution seems a reasonable option at present.

Generally speaking, TFTs should not be carried out routinely in the intensive care setting unless there is a suspicion of thyroid dysfunction, based on past history or clinical evaluation. The goal of TFTs in the ICU should mainly be the identification of previously unrecognized thyroid dysfunction that would require therapeutic intervention. When hypothyroidism is suspected clinically in an ICU patient (e.g. hypothermia, bradycardia, respiratory acidosis, pleural effusions, failure to wean), and the evaluation suggests central hypothyroidism, one should consider, that the probability of euthyroid sick syndrome is much higher than the pituitary or hypothalamic disease. If hyperthyroidism is suspected (e.g. tachyarrhythmias, widened pulse pressure, respiratory alkalosis, high-output heart failure) and low TSH is detected, true hyperthyroidism, is unlikely unless the TSH is suppressed fully on a third-generation assay and the free $T_{4}$ is elevated or at least in the upper limits of the normal range. If the free $\mathrm{T}_{4}$ is low or low-normal, the patient is probably not hyperthyroid. Because of inaccuracy of all free $T_{4}$ assays in this setting, however, repeating the free $T_{4}$ by another method is advised before firmly establishing the diagnosis, especially if clinical suspicion persists.

\section{CONCLUSION}

The evaluation of altered thyroid function parameters in systemic illness and stress remains a complex issue and presents many diagnostic problems because changes occur at all levels of the hypothalamic-pituitary-thyroid axis. Unique changes in thyroid function parameters are observed in various relevant clinical states, including starvation and fasting, cardiac disease, renal disease, hepatic disease and infection. Many pharmacologic agents also cause changes in thyroid economy that can complicate the interpretation of thyroid function parameters in systemic illness. Whether alterations in thyroid parameters during critical illness represent adaptive changes to conserve energy expenditure by reducing metabolic activity is still debatable. According to current data thyroid hormone replacement therapy has not been shown to be of benefit in the vast majority of these patients. $\mathrm{LT}_{3}$, however, appears to slightly improve hemodynamic and neurohumoral variables in patients with congestive heart failure, these benefits possibly representing a pharmacologic effect of $\mathrm{T}_{3}$ rather than a physiologic hormonal replacement effect.

Establishing thyroid dysfunction based on a single set of TFTs may be misleading. Careful clinical evaluation, knowledge of hospital course and of recent therapies are essential for the correct interpretation of such testing. Early pursuit of endocrine consultation may be helpful in difficult situations.

\section{REFERENCES}

1. Plank LD, Connolly AB, Hill GL, 1998 Sequential changes in the metabolic response in severely septic patients during the first 23 days after onset of peritonitis. Ann Surg 228: 146-158.

2. Fong Y, Marono MA, Moldawer LL, et al, 1990 The acute splanchnic and peripheral tissue metabolic response to endotoxin in humans. J Clin Invest 85: 1896-1904.

3. Farwell AP, 2003 Sick euthyroid syndrome in the intensive care unit. In: Irwin RS, Rippe JM, (eds), Irwin 
and Rippe's Intensive Care Medicine, Philadelphia, PA: Lippincott Williams \& Wilkins, pp; 1205-1216.

4. DeGroot LJ, 2003 'Non-thyroidal illness syndrome' is functional central hypothyroidism, and if severe, hormone replacement is appropriate in light of present knowledge. J Endocrinol Invest 26: 1163-1170.

5. Adler SM, Wartofsky L, 2007 The nonthyroidal illness syndrome. Endocrinol Metab Clin North Am 36: 657-672.

6. Brierre S, Kumari R, Deboisblanc BP, 2004 The endocrine system during sepsis. Am J Med Sci 328: 238-247.

7. Hamrahian AH, Oseni TS, Arafah BM, 2004 Measurements of serum free cortisol in critically ill patients. $\mathrm{N}$ Engl J Med 350: 1629-1638.

8. Burman KD, Wartofsky L, 2001 Endocrine and metabolic dysfunction syndromes in the critically ill: thyroid function in the intensive care unit setting. Crit Care Clin 17: 43-57.

9. Mortoglou A, Candiloros, 2004 The serum triiodothyronine to thyroxine (T3/T4) ratio in various thyroid disorders and after Levothyroxine replacement therapy. Hormones (Athens) 3: 120-126.

10. Peeters RP, Wouters PJ, Kaptein E, van Toor H, Visser TJ, Van den Berghe G, 2003 Reduced activation and increased inactivation of thyroid hormone in tissues of critically ill patients. J Clin Endocrinol Metab 88: 3202-3211.

11. Peeters RP, Wouters PJ, van Toor H, Kaptein E, Visser TJ, Van den Berghe G, 2005 Serum 3,3',5'-triiodothyronine (rT3) and 3,5,3'-triiodothyronine/rT3 are prognostic markers in critically ill patients and are associated with postmortem tissue deiodinase activities. J Clin Endocrinol Metab 90: 4559-4565.

12. Peeters RP, Kester MH, Wouters PJ, et al, 2005 Increased thyroxine sulfate levels in critically ill patients as a result of a decreased hepatic type I deiodinase activity. J Clin Endocrinol Metab 90: 6460-6465.

13. Arem R, Wiener GJ, Kaplan SG, Kim HS, Reichlin S, Kaplan MM, 1993 Reduced tissue thyroid hormone levels in fatal illness. Metabolism 42: 1102-1108.

14. Chopra IJ, Williams DE, Orgiazzi J, Solomon DH, 1975 Opposite effects of dexamethasone on serum concentrations of 3,3',5'triiodothyronine (reverse T3) and 3,3'5-triiodothyronine (T3). J Clin Endocrinol Metab 41: 911-920.

15. Chopra IJ, Huang TS, Beredo A, Solomon DH, Chua Teco GN, Mead JF, 1985 Evidence for an inhibitor of extrathyroidal conversion of thyroxine to 3,5,3' -triiodothyronine in sera of patients with nonthyroidal illnesses. J Clin Endocrinol Metab 60: 666-672.

16. Van der Poll T, Romijn JA, Wiersinga WM, Sauerwein HP, 1990 Tumor necrosis factor: a putative mediator of the sick euthyroid syndrome in man. J Clin Endocrinol Metab 71: 1567-1572.

17. Stouthard JM, van der Poll T, Endert E, et al, 1994 Effects of acute and chronic interleukin-6 administration on thyroid hormone metabolism in humans. J Clin
Endocrinol Metab 79: 1342-1346.

18. Corssmit EP, Heyligenberg R, Endert E, Sauerwein HP, Romijn JA, 1995 Acute effects of interferon-alpha administration on thyroid hormone metabolism in healthy men. J Clin Endocrinol Metab 80: 3140-3144.

19. Chopra IJ, 1976 An assessment of daily production and significance of thyroidal secretion of 3, 3', 5'-triiodothyronine (reverse T3) in man. J Clin Invest 58: 32-40.

20. Kaptein EM, 1996 Thyroid hormone metabolism and thyroid diseases in chronic renal failure. Endocr Rev 17: 45-63.

21. Ricart-Engel W, Fernndez-Real JM, Gonzalez-Huix F, del Pozo M, Mascaro J, Garcia-Bragado F, 1996 The relation between thyroid function and nutritional status in HIV-infected patients. Clin Endocrinol (Oxf) 44: 53-58.

22. Afandi B, Vera R, Schussler GC, Yap MG, 2000 Concordant decreases of thyroxine and thyroxinebinding protein concentrations during sepsis. Metabolism 49: 753-754.

23. Wartofsky L, Burman KD, 1982 Alterations in thyroid function in patients with systemic illness:the "euthyroid sick syndrome”. Endocr Rev 3: 164-217.

24. Kaptein EM, Grieb DA, Spencer C, Wheeler WS, Nicoloff JT, 1981 Thyroxine metabolism in the low thyroxine state of critical nonthyroidal illnesses. J Clin Endocrinol Metab 53: 764-771.

25. Chopra IJ, 1998 Simultaneous measurement of free thyroxine and free 3,5,3-triiodothyronine in undiluted serum by direct equilibrium dialysis/radioimmunoassay: evidence that free triiodothyronine and free thyroxine are normal in many patients with the low triiodothyronine syndrome. Thyroid 8: 249-257.

26. Chopra IJ, Teco GN, Mead JF, Huang TS, Beredo A, Solomon DH, 1985 Relationship between serum-free fatty acids and thyroid hormone-binding inhibitor in nonthyroid illnesses. J Clin Endocrinol Metab 60: 980-984.

27. Chopra IJ, 1997 Clinical review 86: euthyroid sick syndrome: is it a misnomer? J Clin Endocrinol Metab 82: 329-334.

28. Ilias I, Stamoulis K, Armaganidis A, et al, 2007 Contribution of endocrine parameters in predicting outcome of multiple trauma patients in an intensive care unit. Hormones (Athens) 6: 218-226.

29. Spencer CA, LoPresti JS, Patel A, et al, 1990 Applications of a new chemiluminometric thyrotropin assay to subnormal measurement. J Clin Endocrinol Metab 70: 453-460.

30. De Jongh FE, Jobsis AC, Elte JW, 2001 Thyroid morphology in lethal non-thyroidal illness: A post-mortem study. Eur J Endocrinol 144: 221-226.

31. Van den Berghe G, de Zegher F, Baxter RC, et al, 1998 Neuroendocrinology of prolonged critical illness: Effects of exogenous thyrotropin releasing hormone and its combination with growth hormone secretagogues. J Clin Endocrinol Metab 83: 309-319.

32. Fliers E, Guldenaar SE, Wiersinga WM, Swaab DF, 1997 Decreased hypothalamic thyrotropin-releasing hormone 
gene expression in patients with nonthyroidal illness. J Clin Endocrinol Metab 82: 4032-4036.

33. Arem R, Wiener GJ, Kaplan SG, Kim HS, Reichlin S, Kaplan MM, 1993 Reduced tissue thyroid hormone levels in fatal illness. Metabolism 42: 1102-1108.

34. Wehmann RE, Gregerman RI, Burns WH, Saral R, Santos GW, 1985 Suppression of thyrotropin in the low thyroxine state of severe nonthyroidal illness. N Engl J Med 312: 546-552.

35. Papanicolaou DA, 2000 Euthyroid sick syndrome and the role of cytokines. Rev Endocr Metab Disord 1: 43-48.

36. Van den Berghe G, de Zegher F, Lauwers P, 1994 Dopamine and the sick euthyroid syndrome in critical illness. Clin Endocrinol (Oxf) 41: 731-737.

37. Burmeister LA, 1995 Reverse T3 does not reliably differentiate hypothyroid sick syndrome from euthyroid sick syndrome. Thyroid 5: 435-441.

38. Hamblin PS, Dyer SA, Mohr VS, et al, 1986 Relationship between thyrotropin and thyroxine changes during recovery from severe hypothyroxinemia of critical illness. J Clin Endocrinol Metab 62: 717-722.

39. Franklyn JA, Black EG, Betteridge J, Sheppard MC, 1994 Comparison of second and third generation methods for measurement of serum thyrotropin in patients with overt hyperthyroidism, patients receiving thyroxine therapy, and those with nonthyroidal illness. J Clin Endocrinol Metab 78: 1368-1371.

40. Stockigt JR, 1996 Guidelines for diagnosis and monitoring of thyroid disease: nonthyroidal illness.Clin Chem 42: 188-192.

41. Mebis L, Langouche L, Visser TJ, Van den Berghe G, 2007 The type II iodothyronine deiodinase is up-regulated in skeletal muscle during prolonged critical illness. J Clin Endocrinol Metab 92: 3330-3333.

42. Peeters RP, Van der Geyten S, Wouters PJ, et al, 2005 Tissue thyroid hormone levels in critical illness. J Clin
Endocrinol Metab 90: 6498-6507.

43. Slag MF, Morley JE, Elson MK, Crowson TW, Nuttall FQ, Shafer RB, 1981 Hypothyroxinemia in critically ill patients as a predictor of high mortality. JAMA 245 : 43-45.

44. Maldonado LS, Murata GH, Hershman JM, Braunstein GD, 1992 Do thyroid function tests independently predict survival in the critically ill? Thyroid 2:119-123.

45. Iervasi G, Pingitore A, Landi P, et al, 2003 Low-T3 syndrome: a strong prognostic predictor of death in patients with heart disease. Circulation. 107: 708-713.

46. Pingitore A, Landi P, Taddei MC, Ripoli A, L'Abbate A, Iervasi G, 2005 Triiodothyronine levels for risk stratification of patients with chronic heart failure. Am J Med 118: 132-136.

47. Vexiau P, Perez-Castiglioni P, Socie G, et al, 1993 The "euthyroid sick syndrome": incidence, risk factors and prognostic value soon after allogeneic bone marrow transplantation. Br J Haematol 85: 778-782.

48. Brent GA, Hershman JM, 1986 Thyroxine therapy in patients with severe nonthyroidal illnesses and low thyroxine concentration. J Clin Endocrinol Metab 63: 1-8.

49. Acker CG, Singh AR, Flick RP, Bernardini J, Greenberg A, Johnson JP, 2000 A trial of thyroxine in acute renal failure. Kidney Int 57: 293-298.

50. Acker CG, Flick R, Shapiro R, et al, 2002 Thyroid hormone in the treatment of post-transplant acute tubular necrosis (ATN). Am J Transplant 2: 57-61.

51. Becker RA, Vaughan GM, Zeigler MG, et al, 1982 Hypermetabolic low triiodothyronine syndrome of burn injury. Crit Care Med 10: 870-875.

52. Spencer C, Eigen A, Shen D, et al, 1987 Specificity of sensitive assays of thyrotropin (TSH) used to screen for thyroid disease in hospitalized patients. Clin Chem 33: 1391-1396. 